\title{
Fertility Desire and Contraceptive Utilization among People Living With HIVIAIDS on ART in Hosanna Town, Southern Ethiopia
}

\author{
Mitsiwat Abebe $^{1^{*}}$, Adamu Addissie $^{2}$, Tesfaye Regassa $^{3^{*}}$ \\ ${ }^{1}$ Ambo University, College of Medical and Health sciences, Ambo, Ethiopia \\ ${ }^{2}$ School of Public Health, Addis Ababa University, Post Box No: 9086, Addis Ababa, Ethiopia \\ ${ }^{3}$ College of Medical and Health Sciences, Wollega University, Post Box No: 395, Nekemte, Ethiopia
}

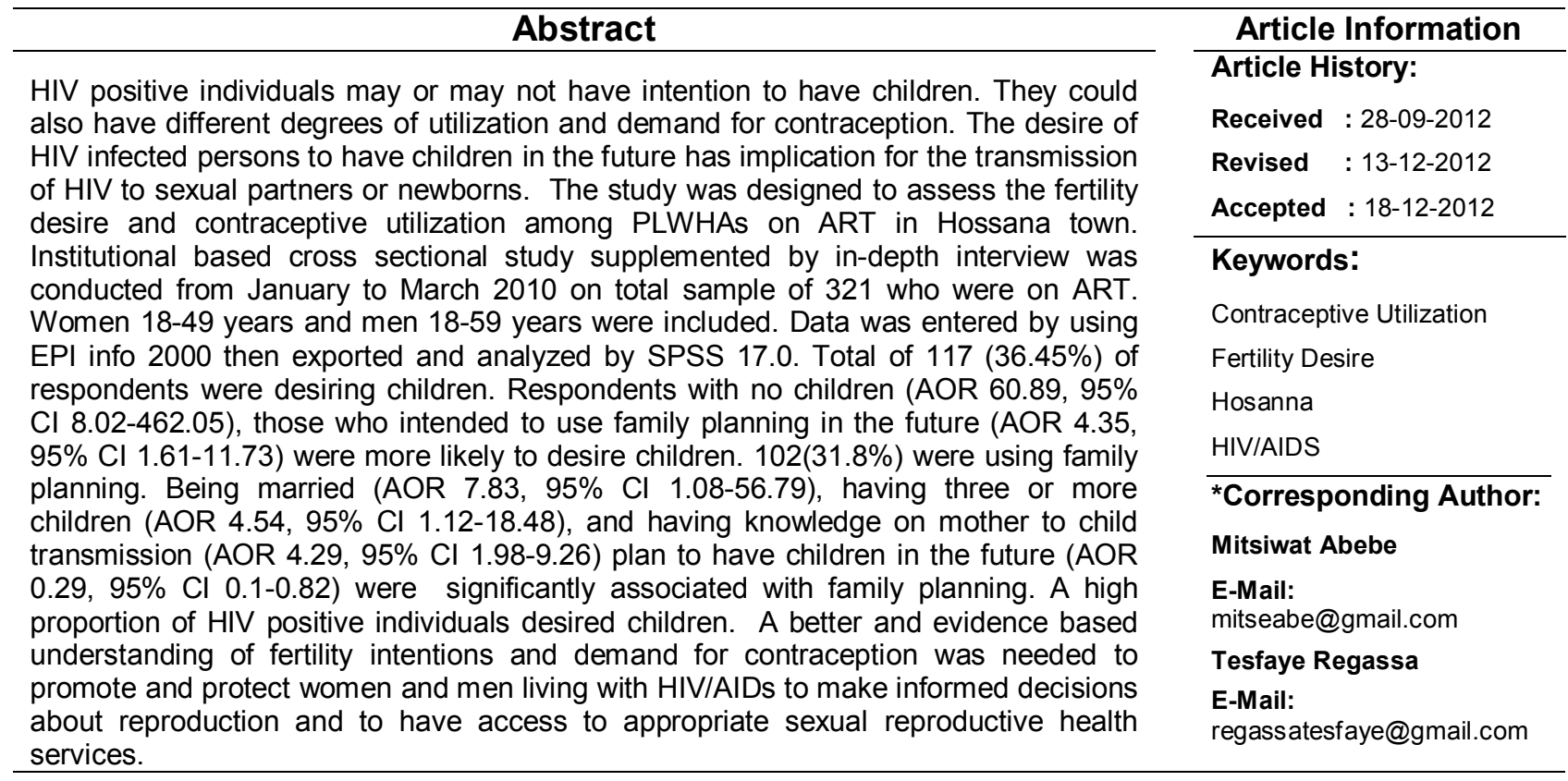

\section{INTRODUCTION}

Ethiopia is currently one of the countries most seriously affected by HIVIAIDS with adult HIV prevalence of $2.1 \%, 7.7$ in urban and 0.9 in rural. Heterosexual HIV transmissions followed by mother to child transmission are responsible for most infection in Ethiopia (FHAPCO, 2006).

ART restores health and fertility in people living with HIV and drastically reduces Mother-toChild Transmission (MTCT) of HIV. As major efforts are under way to expand access to this life-saving ART in sub-Saharan Africa, thousands of men and women on ART are resuming socially productive and sexually active lives involving protected and unprotected sex with or without a desire for children (Cooper et al., 2007). Numerous behavioral and contextual factors interact in a complex way to determine intended and unintended reproductive outcomes among women living with HIV. Age, marital, educational, and socioeconomic status, cultural and religious beliefs, sexual behaviour as well as family size and losses, and access to family planning services are documented predictors of pregnancies (Cooper et al., 2007; Homsy, et al., 2009; Tamene and Fantahun, 2007).

Some HIV-positive women choose to conceive, despite the chances of a poor 
pregnancy outcome. Other sexually active, HIVpositive women want contraception. Providers need to understand how to counsel and serve HIV-positive women, and providers should know that some HIV-positive women will not reveal to them that they are infected (Nam, 2009).

Without intervention PLHIV women has a 25$50 \%$ risk of infecting her baby and use of combination of ART during pregnancy and labor, delivery by Caesarean section and avoidance of breast feeding are proved measures which have reduced the risk of vertical transmission to less than $2 \%$. This makes positive parenting a viable option at least in countries where ART is widely available (Elizabeth and Ellen, 2001).

Study done in South Africa among HIVpositive women indicated wanting to have or having children as life expectancy has improved. HIV positive men and women give value to pregnancy and child birth with improved access to PMTCT and ART (Nduna and Farlane 2009).

More than $80 \%$ of all women living with HIV and their partners are in their reproductive years, many will continue to desire children after learning their positive status. Others may wish to regulate their fertility, so that they can decide whether to try for a pregnancy and when (Craft, et al. 2007). Thus the study tries to assess fertility desire and contraceptive utilization among people living with HIVIAIDs on ART follow up care Hosanna town, southern Ethiopia.

\section{MATERIALS AND METHODS}

Institutional based cross sectional study supplemented by in-depth interview was conducted in Hosanna Town which is located $232 \mathrm{~km}$ South of Addis Ababa from January to March 2010. The number of PLHIV ever enrolled, ever started and on ART in the town was 1392, 679 and 472 respectively (FHAPCO, 2006). During the study period the number of PLHIV on ART were 621 in the hospital and 20 in the health center. PLHIV who had at least one visit to the selected ART units and age group 18-49 for women and 18-59 for men were the source population.

The sample size was calculated using single proportion formula. Fertility desire of $21.6 \%$ which was obtained from Bahir Dar study (Fentahun, 2008), $4.5 \%$ marginal error, $Z_{\alpha / 2}$ at $95 \%$ confidence level was used. The total sample calculated was 321 .
The calculated sample size was used to recruit study subjects from the selected ARV treatment units proportional to the number of PLHIV in both institutions. Eligible persons were included in the study consecutively. For purposive sampling, study subjects were selected based on their sex, age, number of children, marital status and education, and family planning use. The interview included respondents and key informants (health care provider working in PMTCT, VCT, ART and FP department) till saturation of information.

For quantitative data structured questionnaire was used after training and pretesting the questionnaire for two days. For in-depth interview, interview guide was used. For quantitative, data were collected by health officer and Nurse working at ART clinic. The in-depth interview was carried out by the principal investigator supported by assistant after the purpose of the study has been informed to the study subjects.

Data were entered to EPI info, cleaned and were analyzed using SPSS version 17. Bivariate analysis using bivariate logistic regression was done to see the crude association between the independent variables and the dependent variables. The final step of analysis was multivariate analysis using multiple logistic regression technique to control confounding. Statistical significance was determined through a $95 \%$ confidence interval for fertility desire and family planning.

For qualitative data all the audio tape record interview were transcribed and translated to English, collapsed into dominant thematic areas to facilitate analysis. Finally the concepts were refined in to major themes. Ethical approval was obtained from the Institutional Review Board of Medical Faculty, Addis Ababa University.

\section{RESULTS}

\section{Socio-Demographic Characteristics of the Respondents}

A total of 321 participants were included, of those were $226(70.4 \%)$ female and $95(29.6 \%)$ male. The mean age was 32.2 years. Half of $(51.4 \%)$ of the respondents were in the age group of $30-39$ years. One hundred eighty four (57.3\%) of respondents have attended secondary school. With regard to occupation $115(35.8 \%)$, $74(23.1 \%), 61(19 \%)$, of the respondents were unemployed, daily laborer, house wife respectively. With regard to marital status, 158(49.2\%) were married (Table 1 ). 
Table 1: Socio-demographic characteristics of PLWAs attending ARV treatment units, Hossana, Ethiopia, 2010.

\begin{tabular}{|c|c|c|}
\hline Characteristics $(n=321)$ & Number & Percent \\
\hline \multicolumn{3}{|l|}{ sex } \\
\hline Female & 226 & 70.4 \\
\hline Male & 95 & 29.6 \\
\hline \multicolumn{3}{|l|}{ Age } \\
\hline $18-29$ & 102 & 31.8 \\
\hline $30-39$ & 165 & 51.4 \\
\hline $45 \pm$ & 54 & 16.8 \\
\hline \multicolumn{3}{|l|}{ Educational status } \\
\hline Illiterate/read and write & 81 & 25.2 \\
\hline Primary & 35 & 10.9 \\
\hline Secondary & 184 & 57.3 \\
\hline Postsecondary & 21 & 6.5 \\
\hline \multicolumn{3}{|l|}{ Current marital status } \\
\hline Married & 158 & 49.2 \\
\hline Widowed & 93 & 29 \\
\hline Divorced & 49 & 15.3 \\
\hline Single & 17 & 5.3 \\
\hline Other & 4 & 1.2 \\
\hline \multicolumn{3}{|l|}{ Occupation } \\
\hline Unemployed & 115 & 35.8 \\
\hline Daily labor & 74 & 23.1 \\
\hline House wife & 61 & 19 \\
\hline Merchant & 32 & 10 \\
\hline Government employee & 16 & 5 \\
\hline Others ${ }^{* *}$ & 23 & 7.12 \\
\hline
\end{tabular}

${ }^{* *}$ Private, self employed, house maid

\section{Sexual Behaviour, Condom Use and Reproductive Health Characteristics}

One hundred nineteen $(37.07 \%)$ of the respondents had sex during the six months prior to survey of which $86(72.27 \%)$ respondents used condom. Majority $76(88.37 \%)$ applied condom consistently. Forty-nine (15.26\%) of the respondents respond as they practice multipartner sex within the past six months preceding the survey.

Sixty six $(20.56 \%)$ had history of abortion by them /their partner and 53(16.51\%) had history of STI. From those who had history of abortion, $52(78.79 \%)$ reported that the time of occurrence was before acquiring HIV. Almost majority of the respondents $291(90.65 \%)$ had no information on emergency contraceptive but only $30(9.35 \%)$ and from this thirty, $20(66.67 \%)$ had used it if required. Reason for not desiring to use
Emergency Contraceptive wanted a child $5(50 \%)$ (Table 2).

\section{Fertility Intention}

Two hundred eighty two $(87.86 \%)$ of the respondents had at least one child, $148(46.11 \%)$ of them had three or more children. Thirty-six $(37.9 \%)$ male and $81(35.8 \%)$ female expressed the desire for children, giving a total of 117 $(36.45 \%)$ of all respondents. Out of those desiring children $72(61.5 \%)$ desired to have one child.

Respondents gave different reason for not wanting children in the future; from these $138(67.6 \%)$ since they had enough children, $71(34.8 \%)$ fear of mother to child transmission, $25(12.3 \%)$ health professional advice and the remaining $18(8.8 \%)$ fear that child bearing may further compromise their heath. 
Table 2: Sexual behaviour, condom use, reproductive characteristics among PLWHAs attending ARV Treatment unit, Hossana, Ethiopia, 2010.

\begin{tabular}{|c|c|c|}
\hline Characteristics & Number & Percent \\
\hline \multicolumn{3}{|l|}{ Had sex in the past six months $(n=321)$} \\
\hline Yes & 119 & 37.07 \\
\hline No & 202 & 62.93 \\
\hline \multicolumn{3}{|l|}{ Have used condom(n=119) } \\
\hline Yes & 86 & 72.27 \\
\hline No & 33 & 27.73 \\
\hline \multicolumn{3}{|l|}{ How often $(n=86)$} \\
\hline Always & 76 & 88.37 \\
\hline Sometimes & 10 & 11.63 \\
\hline \multicolumn{3}{|l|}{ Practice multi partner $\operatorname{sex}(n=321)$} \\
\hline Yes & 49 & 15.26 \\
\hline No & 272 & 84.74 \\
\hline \multicolumn{3}{|l|}{ Any history of abortion( $n=321)$} \\
\hline Yes & 66 & 20.56 \\
\hline No & 255 & 79.44 \\
\hline \multicolumn{3}{|l|}{ When was the time $(n=66)$} \\
\hline Before acquiring HIV & 52 & 78.79 \\
\hline After acquiring HIV & 12 & 18.18 \\
\hline Don't remember & 2 & 3.03 \\
\hline \multicolumn{3}{|l|}{ Any history of STI ( $n=321)$} \\
\hline Yes & 53 & 16.51 \\
\hline No & 268 & 83.49 \\
\hline \multicolumn{3}{|c|}{ Knowledge about Emergency Contraceptive ( $n=321$ ) } \\
\hline Yes & 30 & 9.35 \\
\hline No & 291 & 90.65 \\
\hline \multicolumn{3}{|l|}{ Do use it if required $(n=30)$} \\
\hline Yes & 20 & 66.67 \\
\hline No & 10 & 33.33 \\
\hline \multicolumn{3}{|c|}{ Reason for not using Emergency Contraceptive $(n=10)$} \\
\hline I want a child & 5 & 50 \\
\hline I fear side effect & 3 & 30 \\
\hline Have no knowledge how to use it & 2 & 20 \\
\hline
\end{tabular}

Almost one-fourth $74 \quad(23.05 \%)$ of the respondents expressed that their partner/spouse desire for children and from those partner not desire children cited as had desired number of children $40(48.19 \%)$, his/her health status was deteriorated $26(31.33 \%)$, fear of risk of mother to child transmission and outside pressure $17(20.48 \%)$ have children within one to two years (Table 3).

In bivariate analysis, the characteristics age group 18-29 COR 6.86( 95\% Cl: 3.03-15.52), having post secondary education COR 3.72 (95\% $\mathrm{Cl}$ : 1.35-10.22), being single/non married partner COR 14.91(95\% Cl: 3.12-71.17), having no children or $1-2$ children COR 133.43 (95\% Cl: 29.62-601.00), partner desire for children COR 7.38(95\% Cl: 3.89-14.04), being widowed COR $0.33(0.15-0.72)$ and intention to use FP in the future COR 4.41(95\% Cl: 2.32-8.37)were significantly associated with fertility desire.
In multivariate analysis; subjects who had no children (AOR 60.89, 95\% Cl 8.02-462.05), if partner decide not to have children(AOR $0.02,95 \% \mathrm{Cl} 0.001-0.41)$ and having one child more (AOR $9.43,95 \% \mathrm{Cl} 2.81-31.62$ ) and those participants who will intend to use family planning (AOR 4.35, 95\% Cl 1.61-11.73) were significantly associated with fertility desire (Table 4).

Data of qualitative result indicated that respondents had varied reason for child desire. They describe availability of ARV treatment, PMTCT service, partner desire, to build generation and community pressure. A 37 married, with no child man explained, "Since the start of ART my health is getting improved. So I am fully healthy and have adequate income to have a child, beside this my wife is young and egger to give birth." 
Table 3: Desire for children among PLWHAs on ART, Hosanna, Ethiopia, 2010.

\begin{tabular}{lcc}
\hline Characteristics & Number & percent \\
\hline Current no of children you have(n=321) & 39 & 12.15 \\
No children & 51 & 15.89 \\
One & 83 & 25.86 \\
Two & 148 & 46.11 \\
>Three & & \\
have children in the future(n=321) & 117 & 36.45 \\
Yes & 204 & 63.55 \\
No & & \\
Intention & 6 & 5.1 \\
Time prefer to have child/children(n=117) & 82 & 70.1 \\
<One year & 28 & 23.9 \\
One-two year & 1 & 0.9 \\
>Two year & & \\
Don't know the time & 72 & 61.5 \\
One & 28 & 23.9 \\
Two & 10 & 8.5 \\
Three & 7 & 6 \\
> Three & & \\
No of children you intend to have in the future(n=117) & 138 & 67.6 \\
Have desired no of children & 71 & 34.8 \\
Fear of MTCT risk & 31 & 15.2 \\
Have no adequate income to add another child & 25 & 12.3 \\
Health professional advise not to have a child & 18 & 8.8 \\
Child bearing may further compromise my/my partner health & & \\
Reason for & & \\
Yes & 74 & 23.05 \\
No & 163 & 25.86 \\
Don't know & 5.3 \\
Don't have partner & 163 \\
\hline
\end{tabular}

In addition to the above reason, the respondent's trust on PMTCT was another reason. A 37 years widow who had one child said, "Of course, I heard about preventive medication to protect the child from getting infected and I trust on it. My child was asking me all the time as he wants a sibling".

Similarly key informants responded that participants had child desire like any other people and the reason. VCT-counselor said, "PLHIV like any other people want children. They are eager to find children at least one, their reasons; if they have no child, to add more children, in old age they want care and help from them. Beside their intention I advice them it is good if they stop the intention of fertility because of risk vertical transmission, their economic standard to care for infants. But if they challenge me I give them information on PMTCT service. "

Most of the respondents who did not want a child report different reasons. VCT counselor reported, "Those participants who do not need children put different reasons. The major one is taking my advise into consideration, living in low economic status, thinking that leaving children without parenthood and increasing the number of orphans, fear of the risk of HIV transmission, and fear of stigma and discrimination for their children since they see children of other PLWHAs how they live in the community." 
Mitsiwat Abebe, Adamu Addissie \& Tesfaye Regassa Sci. Technol. Arts Res. J., Oct-Dec 2012, 1(4):38-46

Table 4: Associated factor of fertility desire among PLWHAs in Hossana, Ethiopia 2010.

\begin{tabular}{|c|c|c|c|c|}
\hline \multirow{2}{*}{ Variable } & \multicolumn{2}{|c|}{ Fertility desire } & \multirow{2}{*}{ COR(95\%Cl) } & \multirow{2}{*}{ AOR(95\%Cl) } \\
\hline & Yes n (\%) & No $n(\%)$ & & \\
\hline \multicolumn{5}{|l|}{ Age } \\
\hline $18-29$ & $59(57.8)$ & $43(42.2)$ & $6.86(3.03,15.52)^{\star}$ & $1.30(0.31,5.46)$ \\
\hline $30-39$ & $49(29.7)$ & $116(70.3)$ & $2.11(0.96,4.65)$ & $0.59(0.16,2.23)$ \\
\hline $40+$ & $9(16.7)$ & $45(83.3)$ & 1 & 1 \\
\hline \multicolumn{5}{|l|}{ Sex } \\
\hline Male & $36(37.9)$ & $59(62.1)$ & 1 & 1 \\
\hline Female & $81(35.8)$ & $145(64.2)$ & $0.92(0.56,1.50)$ & $0.34(0.12,1.03)$ \\
\hline \multicolumn{5}{|l|}{ Educational status } \\
\hline Unable to read/ write & 19(26.4) & $53(73.6)$ & 1 & 1 \\
\hline Able to read and write & $3(33.3)$ & $6(66.7)$ & $1.40(.32,6.14)$ & $0.99(0.04,26.48)$ \\
\hline Primary & $15(42.9)$ & $20(57.1)$ & $2.092(0.89,4.90)$ & $3.42(0.66,17.70)$ \\
\hline Secondary & $68(37.0)$ & $116(63.0)$ & $1.64(0.89,2.30)$ & $1.91(0,63,5.79)$ \\
\hline Post secondary & 12(57.1) & $9(42.9)$ & $3.72(1.35,10.22)$ & $1.00(0.1,10.19)$ \\
\hline \multicolumn{5}{|l|}{ Marital status } \\
\hline Married & $63(39.9)$ & $95(60.1)$ & $1.05(0.54,2.02)$ & $5.38(0.30,98.17)$ \\
\hline Single/ Non-married partner & $19(90.5)$ & $2(9.5)$ & $14.91(3.12,71.17)^{\star}$ & $4.31(0.44,42.51)$ \\
\hline Widowed & 16(17.2) & $77(82.8)$ & $0.33(0.15,0.72)^{*}$ & $0.84(0.28,2.48)$ \\
\hline Divorced & 19(38.8) & $30(61.2)$ & 1 & 1 \\
\hline \multicolumn{5}{|l|}{ No of children current have } \\
\hline No child & $37(94.9)$ & $2(5.1)$ & $133.43(29.62,601.00)^{*}$ & $60.89(8.02,462.05)^{\star}$ \\
\hline One & $31(60.8)$ & $20(39.2)$ & $11.20(5.30,23.64)$ & $9.43(2.81,31.62)^{*}$ \\
\hline Two & $31(37.3)$ & $52(62.7)$ & $4.31(2.22,8.36)$ & $2.44(0.76,7.85)$ \\
\hline$>=$ three & 18(12.2) & $130(87.8)$ & 1 & 1 \\
\hline \multicolumn{5}{|l|}{ Partner desire for children } \\
\hline Yes & $58(78.4)$ & $16(21.6)$ & $7.38(3.89,14.04)^{\star}$ & $0.87(0.05,16.35)$ \\
\hline No & $5(6.0)$ & $78(94.0)$ & $0.13(0.05,0.34)$ & $0.02(0.001,0.41)^{*}$ \\
\hline Don't have part/don't know & $54(32.9)$ & $110(67.1)$ & 1 & 1 \\
\hline \multicolumn{5}{|l|}{ Like to use FP in the future } \\
\hline Yes & $33(58.9)$ & 23(41.1) & $4.41(2.32,8.37)^{\star}$ & $4.35(1.61,11.73)^{*}$ \\
\hline No/don't know & $40(24.5)$ & $123(75.5)$ & 1 & 1 \\
\hline
\end{tabular}

\section{Contraceptive Utilization}

One hundred twenty two $(38.01 \%)$ of participants ever use contraceptive before learn their HIV status and 108(33.64) were continuing the contraception after test. Majority of the respondents $96(94.1 \%)$ using condom followed by injectable $11(10.8 \%)$ and similarly respondents those who were not using during the study period desire to use condom $42(75 \%)$ (Table 5).

Table 5: Distributions of PLWHA under follow up care by contraceptive ever use before and after HIV test, Hossana, Ethiopia, 2010.

\begin{tabular}{cll}
\hline Characteristics & \multicolumn{1}{c}{ before $\mathbf{n} \%$} & after $\mathbf{n} \%$ \\
\hline Contraceptive ever use & \multicolumn{1}{c}{$\mathbf{n = 3 2 1}$} & \multicolumn{1}{c}{$\mathbf{n = 3 2 1}$} \\
Yes & $122(38.01)$ & $108(33.64)$ \\
No & $193) 60.12)$ & $208(64.8)$ \\
Don't remember/don't know & $6(1.87)$ & $5(1.56)$ \\
Method & before $(\mathbf{n}=122)$ & after(n=108) \\
Condom & $11(9)$ & $93(86.1)$ \\
Pills(OCP),COC & $31(25.4)$ & $3(2.8)$ \\
Inject able & $86(70.5)$ & $16(14.8)$ \\
Implants & $3(2.5)$ & $1(0.9)$ \\
Tubal legation & & $1(0.9)$ \\
\hline
\end{tabular}


Mitsiwat Abebe, Adamu Addissie \& Tesfaye Regassa

In bivariate analysis, being secondary (COR 2.16, 95\% Cl: 1.12-4.17) and above education (COR 3.11, 95\% Cl: 1.10-8.82), having married (COR 23.74, 95\% Cl: 7.07-79.68), having knowledge on MTCT (COR3.22, 95\% Cl: 1.835.68), no partner COR 0.03(COR 3.22, 95\% Cl: 0.01-0.07) has significant association with current family planning use.
Sci. Technol. Arts Res. J., Oct-Dec 2012, 1(4):38-46

In multi-variate analysis, being married (Adjusted OR 7.83, 95\% Cl: 1.08-56.79), having three or more children (AOR 4.54, 95\% Cl: $1.12-$ 18.48), those having knowledge on mother to child transmission (AOR 4.29, 95\% Cl: 1.98-9.26) and like children in the future (AOR $0.29,95 \% \mathrm{Cl}$ : $0.1-0.82$ ) had significant association with fertility desire (Table 6).

Table 6: Associated factor of current FP use among PLWHAs in Hossana, Ethiopia 2010.

\begin{tabular}{|c|c|c|c|c|}
\hline \multirow[b]{2}{*}{ Variable } & \multicolumn{2}{|c|}{ Currently Using FP } & \multirow[b]{2}{*}{ COR(95\%Cl) } & \multirow[b]{2}{*}{ AOR(95\%Cl) } \\
\hline & $\begin{array}{l}\text { Yes } \\
\text { n (\%) }\end{array}$ & $\begin{array}{c}\text { No } \\
n(\%)\end{array}$ & & \\
\hline \multicolumn{5}{|l|}{ Age } \\
\hline $18-29$ & $35(34.3)$ & $67(65.7)$ & $1.65(0.78,3.47)$ & $2.64(0.75,9.290$ \\
\hline $30-39$ & $54(32.7)$ & 111(67.3) & $1.53(0.76,3.10)$ & $1.80(0.61,5.30)$ \\
\hline $40+$ & $13(24.1)$ & $41(75.9)$ & 1 & 1 \\
\hline \multicolumn{5}{|l|}{ Sex } \\
\hline Male & $36(37.9)$ & $59(62.1)$ & 1 & 1 \\
\hline Female & $66(29.2)$ & $160(708)$ & $0.68(0.41,1.12)$ & $1.15(0.50,2.67)$ \\
\hline Educational status & & & & \\
\hline Unable to read/ write & 14(19.4) & $58(80.6)$ & 1 & 1 \\
\hline $\begin{array}{l}\text { Able to read and write } \\
\text { Primary }\end{array}$ & $\begin{array}{l}3(33.3) \\
13(37.1)\end{array}$ & $\begin{array}{l}6(66.7) \\
22(62.9)\end{array}$ & $\begin{array}{l}2.07(0.46,0.32)^{*} \\
2.45(1.00,6.02)^{*}\end{array}$ & $\begin{array}{l}1.11(0.12,10.01) \\
0.86(0.25,2.98)\end{array}$ \\
\hline Secondary & $63(34.2)$ & $121(65.8)$ & $2.16(1.12,4.17)^{\star}$ & $1.01(0.39,2.63)$ \\
\hline Post secondary & $9(42.9)$ & $12(57.1)$ & $3.11(1.10,8.82)^{*}$ & $0.58(0.14,2.49)$ \\
\hline \multicolumn{5}{|l|}{ Marital status } \\
\hline Married & $96(60.8)$ & $62(39.2)$ & $23.74(7.07,79.68)^{*}$ & $7.83(1.08,56.79)^{*}$ \\
\hline Single/ Non-married partner & $2(9.5)$ & 19(90.5) & $1.61(0.25,10.44)$ & $2.34(0.26,20.85)$ \\
\hline Widowed & $1(1.1)$ & $92(98.9)$ & $0.17(.021,0.65)^{*}$ & $0.20(0.02,2.12)$ \\
\hline Divorced & $3(6.1)$ & 46(93.9) & 1 & 1 \\
\hline \multicolumn{5}{|l|}{ No of children current have } \\
\hline No child & $8(20.5)$ & $31(79.5)$ & 1 & 1 \\
\hline One & $12(23.5)$ & $39(76.5)$ & $1.19(0.43,3.28)$ & $2.14(0.53,8.7)$ \\
\hline Two & $28(33.7)$ & $55(66.3)$ & $1.97(0.80,4.86)$ & $2.31(0.62,8.6)$ \\
\hline >=three & $54(36.5)$ & $94(63.5)$ & $2.23(0.96,5.19)$ & $4.54(1.12,18.48)^{*}$ \\
\hline \multicolumn{5}{|l|}{ Partner desire for children } \\
\hline Yes & $44(59.5)$ & $30(40.5)$ & 1 & 1 \\
\hline No & $51(61.4)$ & $32(38.6)$ & $1.09(0.57,2.06)$ & $2.83(0.50,15.92)$ \\
\hline Don't have part/don't know & $7(4.3)$ & $157(95.7)$ & $0.03(0.01,0.07)^{\star *}$ & $6.59(1.07,40.44)^{*}$ \\
\hline \multicolumn{5}{|l|}{ Knowledge on MTCT of HIV } \\
\hline Yes & $83(39.7)$ & $126(60.3)$ & $3.22(1.83,5.68)^{\star *}$ & $4.29(1.98,9.26)^{\star}$ \\
\hline No/ Don’t know & 19(17.0) & $93(83)$ & 1 & 1 \\
\hline \multicolumn{5}{|l|}{ Like children in the future } \\
\hline Yes & $44(37.6)$ & $73(62.4)$ & $1.52(0.94,2.46)$ & $0.29(0.10,0.82)^{\star}$ \\
\hline No & $58(28.4)$ & 146(71.6) & 1 & 1 \\
\hline \multicolumn{5}{|l|}{ Recent CD4 count } \\
\hline$<200$ & $18(42.9)$ & $24(57.1)$ & 1 & 1 \\
\hline $200-500$ & $66(30.0)$ & $154(70.0)$ & $0.57(0.29,1.12)$ & $0.42(0.16,1.14)$ \\
\hline$>500$ & $18(30.5)$ & $41(69.5)$ & $0.59(0.26,1.34)$ & $0.76(0.22,2.63)$ \\
\hline
\end{tabular}

*have significant association at 95\% CL. 
Respondents who use contraceptive gave different reasons for their use; mainly to protect pregnancy, health professional advice and fear of cross infection; reasons for not using FP were family planning and ARV medication interaction, need child in the future and abstained from sex. A 24 year never married, with no child woman expressed, "The health care provider told me that I have to use condom regularly not to get pregnant and protect re-infection with another type of virus."

\section{DISCUSSION}

The study tried to assess fertility desire and contraceptive utilization among PLHIV on ART. $36(37.9 \%)$ male and $81(35.8 \%)$ female respondents expressed the desire for children, giving a total of $117(36.5 \%)$. About $32 \%$ were using FP and $25.6 \%$ want to use family planning in the future. It is consistent with study done in Lesotho (39 \%) (Adir, 2007).

A study done in Zimbabwe indicated that $30.8 \%$ HIV-positive women became pregnant after their diagnosis, with $43.8 \%$ of pregnancies desired. It slightly lower than study done an Addis Ababa which showed $44.7 \%$ of women and $35.2 \%$ of men desired children ((Tamene and Fantahun, 2007)). This is a cause for concern considering its implication for controlling vertical as well as heterosexual transmission. In the absence of medical intervention the risk of MTCT of HIV is up to $25-40 \%$ in Africa (Saha, April 2009). Without intervention has $25-50 \%$ risk of transmission from mother to child but it can be reduced to $2 \%$ by cesarean section in combination of PMTCT ( Elizabeth and Ellen, 2001). This shows that many of these people are from low socio economic status so unable to access optimal care for themselves and to reduce the likely hood of transmission to the new born.

An important factor associated with fertility desire identified in the study was the number of children. Those who had no children were more likely to desire children than who had one or more children, the finding agree with the result of qualitative study. This study was also consistent with study done at Addis Ababa, South Africa and Lesotho (Adir, 2007; Cooper et al., 2007; Tamene and Fantahun, 2007). This is attributed to the socio cultural norms that reflect as they need to build generation.

Another predicting factor associated with decreased likelihood of fertility desire was intention to use family planning in the future. This implies the truth that family planning is important to space or limit birth.
Family planning use was assessed together with fertility desire. The study showed that $38 \%$ of study subjects ever used at list one method of modern FP methods before HIV diagnosis. It was reduced to $33.6 \%$ after HIV diagnosis, to $31.8 \%$ during the study period and $25.6 \%$ need to use in the future, the number was going reduced. This might be due to drug interaction, sero positive result and immediate behavioral change that might occur after HIV diagnosis. This finding is lower than the study done at Addis Ababa (Tamene and Fantahun, 2007). This might be the availability of good quality counseling and integration of FP and ART services at Addis Ababa due to specialized health institutions. The finding has implication for the timing of family planning counseling.

The most common preferred method of family planning after HIV diagnosis and during the study period was condom. It also reflects the presence of method switch from others to condom, also supported by qualitative data. It implies that it is necessary not to rely only on condom rather combination of condom with other modern contraceptive.

Significant proportion (80.2\%) respondents reported that they used condom to prevent other STDs; however, $27.7 \%$ of participants who themselves made sex in the past six months prior to survey not using condom and $11.6 \%$ used irregularly. This has implication for vertical as well as heterosexual transmission of HIV. It also has implication for the chance of unintended pregnancy among the study participants.

\section{CONCLUSION}

Marriage was important factor which has an association with contraceptive use. Those married were more likely to use family planning. Because those participants had frequent sexual contact and fear unintended pregnancy but those without regular partner might in sex rarely or abstained and they perceive less risk of getting pregnancy, these result are consistent with qualitative finding. Those respondents having children of three or more strongly associated with current family planning use. These people may want to limit their number of children with their socio economic status.

Another finding which had strong association was knowledge on mother to child transmission of HIV. Those participants having knowledge /information on mother to child transmission of HIV were more likely using family planning. It is consistent to the study done in Lesotho 
(Adir, 2007). These shows knowledge have influence on family planning use, the service provider should fill the knowledge for those who were having less information. Those participants who desired children in future were less likely to use family planning. This might imply during the study period those participants were not using family planning; they might be pregnant or they desired for children. Two hundred ninety one $(90.65 \%)$ participants had no knowledge on emergency contraceptive and 20(66.67\%) participants who knew about emergency contraceptive wanted to use it if emergency happen which was consistent to study done in South Africa (Saha, 2009). This pave the way to vertical transmissions of HIV if unintended pregnancy, so it has programmatic implication.

\section{REFERENCES}

Adir, T. (2007). Desire for children and unmet need for Contraception among HIV Positive Women. DHS working paper; Demography and Health Research (32).

Cooper, D., Harries, J., Myer, L., Orner, P., Bracken, $\mathrm{H}$. and Zweigenthal, V. (2007). "Life is still going on": Reproductive intentions among HIV-positive women and men in South Africa. Social Science and Medicine 65:274-83.

Craft, SM., Delaney, RO., Bautista, DT., (2007). Pregnancy decisions among women with HIV. AIDS Behaviour 11(6):927-935.

Elizabeth, A. and Ellen, G. (2001). Prevention of mother to child transmission of HIV in Africa: A practical Guide line for programmers SARA. USAID.
Feldman, R., Manchester, J., Maposhere, C. (2002). Positive women: voices and choices. Journal of AIDs care (supplement): 9-14.

Fentahun, T. (2008). Fertility intention and Family Planning utilization among People living with HIVIAIDS in Felege Hiwot Hospital, Bahir Dar, MPH thesis, Addis Ababa University, Addis Ababa.

FHAPCO (2006). Report on progress towards implementation of the Declaration of Commitment on HIVIAIDS. Ethiopia: Federal Democratic Republic of Ethiopia. Addis Ababa, FHAPCO.

Homsy, J., Bunnell, R., Moore, D., King, R., Malamba, S., Nakityo, R., Glidden, D., Tappero, J. and Mermin, J. (2009). Reproductive Intentions and Outcomes among Women on Antiretroviral Therapy in Rural Uganda: A Prospective Cohort Study. PLOS ONE 4.

Nam, F. (2009). Pregnancy and Contraception. India.

Nduna, M. and Farlane, L. (2009). Women Living with HIV in South Africa and Their Concerns about Fertility. AIDS Behavior 13(Supplement):62-5.

Saha, A. (April 2009). Convergence of Sexual and Reproductive Health and HIVIAIDS Services in India. Path HIV-SRH Convergence Project 3:1-2.

Tamene, W. and Fantahun, M. (2007). Fertility desire and family planning demand among HIV positive women and men undergoing treatment in Addis Abba, Ethiopia. African Journal of AIDS research 6(3):223-227. 